\title{
Heart transplantation: new realities, challenges and development- demographics and therapeutics
}

\begin{abstract}
Since the first heart transplant, refinement of donor and recipient selection methods, better donor heart management, and advances in immunosuppression have significantly improved survival. In this first of two articles, a perspective of the current realities of cardiac transplantation is shown, as well as the challenges to sustain services worldwide, and some of the new developments, both presently available and just beyond the horizon. Topics that will be covered in this first part include the donor and recipient demographics, as well as recent advances in transplantation immunology, allograft vasculopathy, and immune tolerance.
\end{abstract}

Keywords: heart failure, transplantation, mechanical circulatory support, immunosuppression
Volume I Issue 3 - 2014

\author{
Babar B Chaudhri \\ Department of Cardiovascular, Thoracic Surgery and \\ Intrathoracic Transplantation, Sir HN Reliance Foundation \\ Hospital, India

\begin{abstract}
Correspondence: Babar B Chaudhri, Department of Cardiovascular, Thoracic Surgery and Intrathoracic Transplantation, Sir HN Reliance Foundation Hospital, Raja Ram Mohan Roy Marg, Mumbai, 40004, India, Tel 91 7738I64236,
\end{abstract} \\ Email bchaudhri@mac.com
}

Received: May 07, 2014 | Published: June 28, 2014
Abbreviations: CHD, congenital heart disease; MCS, mechanical circulatory support; ISHL, international society of heart and lung; HLA, human leukocyte antigen; AMR, antibody mediated rejection; CNIs, calcineurin inhibitors; CAV, coronary allograft vasculopathy; LVADs, left ventricular assist devices; PTLD, post transplant lymphoproliferative disorder

\section{Introduction}

The first human heart transplant performed in South Africa in 1967 by Christiaan Barnard, took considerable advantage of the pioneering experimental work by Alexis Carrel, Frank Mann, Norman Shumway, and Richard Lower. ${ }^{1-4}$ The first heart transplant recipient recovered well initially, but died of pneumonia 18 days later. Initial outcomes were poor, due to a limited understanding of early postoperative complications as well as limited measures to detect and treat rejection and opportunistic infections. The second recipient survived for 19months, but surprisingly died of myocardial infarction. Cardiac allograft vasculopathy was eventually recognized as the cause of this death. ${ }^{3}$ In the UK a moratorium on heart transplantation was declared in 1973 to 1980 . During this interval, cardiac transplantation continued in the US. It recovered due to refinement of donor and recipient selection methods, better donor heart management, and the introduction of cyclosporine. In excess of 88,000 total heart transplants have been performed worldwide. ${ }^{5}$ The International Society of Heart and Lung Transplantation registry currently reports that 1 -year survival after heart transplantation is $81 \%$. The annual mortality thereafter is $4 \%$ per year. The half-life for survival is 10years. Mortality is highest in the first year of transplant, after this the conditional half-life is 13years. The causes of death within the first 6 months are mainly due to graft dysfunction and infection. Late attrition is due to chronic rejection, chronic allograft vasculopathy and malignancies. Heart transplantation is now the optimal treatment for selected patients with end-stage heart failure with 1-year survival is in the region of $90 \%, 5$-year survival rate is approximately $70 \%$, and a median survival in excess of $10 y e a r s .{ }^{5}$ The field of heart transplantation is in evolution. Advances in organ preservation, immune monitoring, and immunosuppressive regimens will lead to further improvement in the quality and the length of life of heart transplant recipients. In this article, the objective is to give a perspective of the current reality of cardiac transplantation as well as challenges to this and the new developments which may help to sustain cardiac transplantation in the future.

\section{Patient demographics}

The patient demographics associated with cardiac transplantation are changing. In the USA, older age is now only a relative contraindication to heart transplantation. Rejection is usually less frequent in older recipients while the incidence of infection and allograft vasculopathy may be higher., ${ }^{6,7}$ Outside of the US, greater proportion of younger patients with complex congenital heart disease (CHD) patients are being referred for evaluation ${ }^{3,5}$. More patients with CHD survive into adulthood and may develop heart failure later in life, despite adequate surgical repair or palliation. ${ }^{8,9} \mathrm{CHD}$ is one of the strongest risk factors for 1-year mortality after heart transplantation in adults. ${ }^{5,8}$ This high initial attrition rate may be due to challenging anatomical arrangements of the heart and great vessels, adhesions from prior surgery, collateral vessels present in CHD; and importantly, a higher incidence of HLA sensitized patients due to multiple transfusions..$^{10}$ More recently, cardiac transplantation has taken place with ABO- incompatible donors. This has increased the donor pool for infants and reduced the mortality rate among infant on the waiting list for transplantation. This will be discussed further in the section "advances in immunology".

There is an increase in the number of patients who require mechanical circulatory support (MCS) as a bridge to transplantation., ${ }^{5,11}$ This has been driven, particularly in the UK, by the paucity of hearts for donation with the aim of buying time on the transplant waiting list. This is due to an increase in the numbers of non-heart beating donors (DCDs), whereby retrieval takes place in a circulation arrested donor, and the increased survival of head injury patients and those with intracranial bleeds who are treated by a decompressive craniotomy, reducing the pool of donors who have raised intracranial pressure and who have coned, resulting in brain stem death. The net result is a retrieval rate for heart transplantation of around 19\%. MCS allows many severely ill adult and pediatric patients to survive until a suitable donor heart is available. Patients with MCS are at increased risk for rejection, infection, stroke, and bleeding. The need for transfusions 
also increased the risk of pre-sensitization..$^{5-7}$ In patients with MCS who undergo transplantation, survival at 1 and 5years is decreased compared to those transplanted without MCS, but is still higher than $80 \%$ and $70 \%$, respectively. ${ }^{5}$

As increasing number of patients are transplanted earlier in life, it is also expected that retransplantation will become more common in the future, retransplantation accounts for less than $3 \%$ of heart transplants. ${ }^{5}$ Survival for retransplanted patients is significantly lower than for other transplant patients. This is due to allosensitisation and the consequence ofyears of immunosuppression. Risk factors for adverse outcomes after retransplantation are early retransplantation after primary transplantation ( $<6$ months), retransplantation for acute rejection, and early allograft failure. ${ }^{12-14}$ When selection criteria for retransplantation excluded these indications, 1-4year survival is comparable to primary transplantation. ${ }^{12,13}$

\section{Advances in donor allocation and selection}

Recipient criteria for heart transplantation include severe symptoms despite maximal medical management, the absence of reversible or surgically amenable heart disease, and where estimated 1 -year survival is less than $50 \%{ }^{15}$ An estimate of functional capacity can be quantified by measurement of peak $\mathrm{O} 2$ consumption (VO2 max). Currently, VO2max remains the single best cardiopulmonary evaluation to predict mortality in heart failure. Patients with low VO2 max $(<12 \mathrm{ml} / \mathrm{min} / \mathrm{kg})$ have high mortality even if treated with beta blockers. International Society of Heart and Lung (ISHLT) guidelines suggest that transplantation should be considered for these patients. Heart failure prognosis scores to estimate survival, such as the Heart Failure Severity Score are useful. This calculates a survival probability on the basis of the presence of ischemic cardiomyopathy, resting heart rate, left ventricular ejection fraction, mean blood pressure, interventricular conduction delay, VO2 max and serum sodium concentration. ${ }^{16}$

The eligibility for transplantation is considered with regard to risk factors, notably pulmonary hypertension. Right heart catheterization should be performed in all potential candidates for heart transplantation to quantify pulmonary vascular resistance ${ }^{16}$ Right heart failure is a substantial cause of mortality as right ventricular failure is likely when post implant pulmonary artery pressures exceed $50 \mathrm{mmHg}$. Patients with chronic heart failure may develop pulmonary hypertension due to elevated left ventricular end diastolic pressure with elevated left atrial and pulmonary venous pressures. This is a reactive form of pulmonary hypertension and may fall when the cardiac output is increased with inotropes or unloaded with nitrate infusions. ${ }^{16}$ The transpulmonary gradient is calculated by subtracting the left atrial filling pressure from the mean pulmonary artery pressure. A fixed transpulmonary gradient in excess of $14 \mathrm{mmHg}$ is associated with greatly elevated risk, and thus this cut off is used in the UK. ${ }^{17}$

\section{Preoperative preparation}

Donor-recipient matching takes place on the basis of urgency, blood group and size ( $80 \%$ or greater of recipient body weight). Organs are generally not used when the recipient has preexisting antibodies to the donor's HLA antigens. Desensitization is possible in selected cases and will be discussed later in this article. The donor heart is assessed by measurement of filling pressures and cardiac output with a Swan Ganz catheter inserted by the organ retrieval team or by direct pressure measurements. Trans-esophageal echocardiography is sometimes used to support the retrieval assessment process. Conditions precluding use of a donor heart are summarized in Table 1. If the donor heart is deemed to be satisfactory, the patient is prepared for surgery. Immunosuppression is given preoperatively, azathioprine and cyclosporine orally $24 \mathrm{~h}$ preoperatively as well as anesthetic premedication. The United Network for Organ Sharing regulates donor heart allocation in the USA. It has a priority system based on the severity of cardiac illness, transportation distance, length of time on the waiting list, and $\mathrm{ABO}$ blood group compatibility. ${ }^{18}$ There is a physiological limit of approximately 4 to $5 \mathrm{~h}$ of ischemia time for the retrieved heart. This prevents national sharing of donor hearts in the US, or matching donor hearts according to human leukocyte antigen (HLA) compatibility. ${ }^{19}$ The allocation process was changed in 1999 to account for medical urgency and to reduce waiting times for blood type $\mathrm{O}$ recipients. ${ }^{18}$ The number of waiting recipients is increasing and sadly the number of donors is falling. This has resulted in a trend to transplant urgent status recipients and to a relaxation of donor acceptance criteria. Post-transplant survival has remained constant despite these changes, due to advances in treatment. ${ }^{19}$ The first step of donor heart acceptance is to rule out any contraindication to heart donation such as significant heart dysfunction, $\mathrm{CHD}$, transmissible diseases, or malignancies (except primary tumors of the central nervous system with low metastatic potential) (Table 1).

Table I Exclusion criteria for donor hearts

$\begin{array}{ll}\text { I } & \text { HIV positivity* } \\ 2 & \text { Significant ventricular arrhythmias } \\ 3 & \text { Echocardiographic abnormalities } \\ 4 & \text { Significant global hypokinesia } \\ 5 & \text { Significant valvular abnormality } \\ 6 & \text { Significant coronary artery disease } \\ 7 & \text { Any acute malignancy with the exclusion of primary brain cancer (unless craniotomy or ventricular shunt has been performed) } \\ 8 & \text { Inadequately treated systemic infection } \\ 9 & \text { Hepatitis B surface antigen positivity, unless recipient is positive } \\ 10 & \text { Significant left ventricular hypertrophy } \\ 11 & \text { Cardiac contusion } \\ 12 & \text { Death from carbon monoxide poisoning with carboxy hemoglobin level }>20 \% \\ 13 & \text { Intravenous drug abuse }\end{array}$

*USA, some cardiac and kidney transplant programs match HIV +ve donors to HIV +ve recipients 
The second step is to match a specific donor to a suitable transplant candidate. Matching is based on $\mathrm{ABO}$ blood group compatibility and body size. Although adult donor hearts must be $\mathrm{ABO}$ compatible with the recipient, this concept has been recently challenged in infants (age $<12$ months) by the successful performance of ABO incompatible heart transplants. ${ }^{20}$ Matching donor and recipient for size is especially important in pulmonary hypertension. In general, a height and weight difference of up to 20 percent is tolerated. In potential recipients with significant pulmonary hypertension, donor size equal or higher than the recipient is usually recommended. In pediatric patients the use of oversized donor hearts has been advocated by many centres with successful outcomes and this mitigates against the low numbers of suitably sized donors. ${ }^{11}$

There are donor characteristics which are associated with adverse outcomes. The use of older donor hearts ( $>40$ year old) is associated with higher peri operative mortality and a higher incidence of later cardiac allograft vasculopathy. ${ }^{5}$ Donor left ventricular hypertrophy (left ventricular wall thickness greater than $14 \mathrm{~mm}$ ) is associated with decreased long-term survival. ${ }^{21}$ Gender mismatch with a female donor heart transplanted into a male is associated with worse 5 and 10 year survival. ${ }^{5}$ Donor heart allocation from hepatic $\mathrm{C}$ positive patients is also sometimes considered for recipients on an alternate list. Donor hepatitis $\mathrm{C}$ virus is associated with a decrease in 1 and 5 year mortality in recipients older than 39years irrespective of recipient hepatitis $\mathrm{C}$ virus status. ${ }^{22,23}$ In the USA, some cardiac and kidney transplant programs match HIV +ve donors to HIV +ve recipients. In the modern era of HIV care, with highly effective antiretroviral medications, a universal ban on transplants from HIV-infected donors may no longer be justified. ${ }^{24,25}$ High volume centres are also associated with better post-transplant outcomes. ${ }^{5}$

\section{Advances in immunology}

As understanding of the pathways involved in immune activation has evolved, there have been many breakthroughs in transplantation medicine, including the development of novel immunosuppressive agents. Signal 1 is provided when antigen-presenting cells and antigens activate the $\mathrm{T}$ cell receptor. Signal 2 (co stimulation) occurs when CD80 (B7-1) and CD86 (B7-2) on the antigenpresenting cells engage CD28. Both signals activate important signal transduction pathways \{calcineurin, RAS-mitogen-activated protein kinase (MAP-K) pathway, and the nuclear factor-kappa B (NF-kB) pathway\}. These pathways lead to expression of many molecules, including interleukin (IL)-2 and IL-15. Interleukin-2 and other cytokines then activate the "target of rapamycin" pathway to provide the trigger for cell proliferation (signal3). AP-1 "activating protein 1; CDK" cyclins-dependent protein kinase; IKK "serine-threonine protein kinase; JAK3 "Janus kinase 3; MHC "myosin heavy chain; mRNA "messenger ribonucleic acid; mTOR" mammalian target of rapamycin; NFAT "nuclear factor of activated T cells; PKC "protein kinase C; S-1-P "sphingosine-1-phosphate; TCR" T cell receptor with permission, from Halloran. The all immune response starts with the activation of antigen-presenting cells of donor and host origin. Once activated, antigen presenting cells engage alloantigen-reactive naive $\mathrm{T}$ cells and central memory T cells. ${ }^{25-28}$ Naive $\mathrm{T}$ cells and memory $\mathrm{T}$ cells re circulate in the secondary lymphoid organs or undergo clonal expansion and differentiate into effector cells when activated. Direct antigen presentation to antigen-experienced cells by graft endothelium may also occur. ${ }^{27,29} \mathrm{~T}$ cell activation requires the stimulation of 3 signal pathways (Figure 1) ${ }^{27}$ The first signal originates from the interaction between the major histocompatibility complex/peptide complex and the T cell receptor/CD3 complex. Antigen-presenting cells provide costimulation when the CD80 and CD86 (B7) interact with the CD28 on $\mathrm{T}$ cells. The second signal (co stimulation) occurs by the interaction of CD80 and CD86 with CD152 (CTLA-4) as well as the interaction of CD40 and CD154. These signals lead to the activation of the calciumcalcineurin pathway, mitogen-activated protein kinase pathway, and the nuclear factor-kappa B pathway..$^{27,30}$ This leads to the expression of interleukin-2 as well as molecules such as CD154 and CD25. The third signal of the alloimmune response occurs when interleukin-2 and other cytokines activate the target of rapamycin pathway that leads to cell proliferation and differentiation. B cells are also activated when antigens interact with B cell receptors in secondary lymphoid organs and in the transplanted organ. Complement and inflammatory mediators contribute to the alloimmune response. ${ }^{27}$

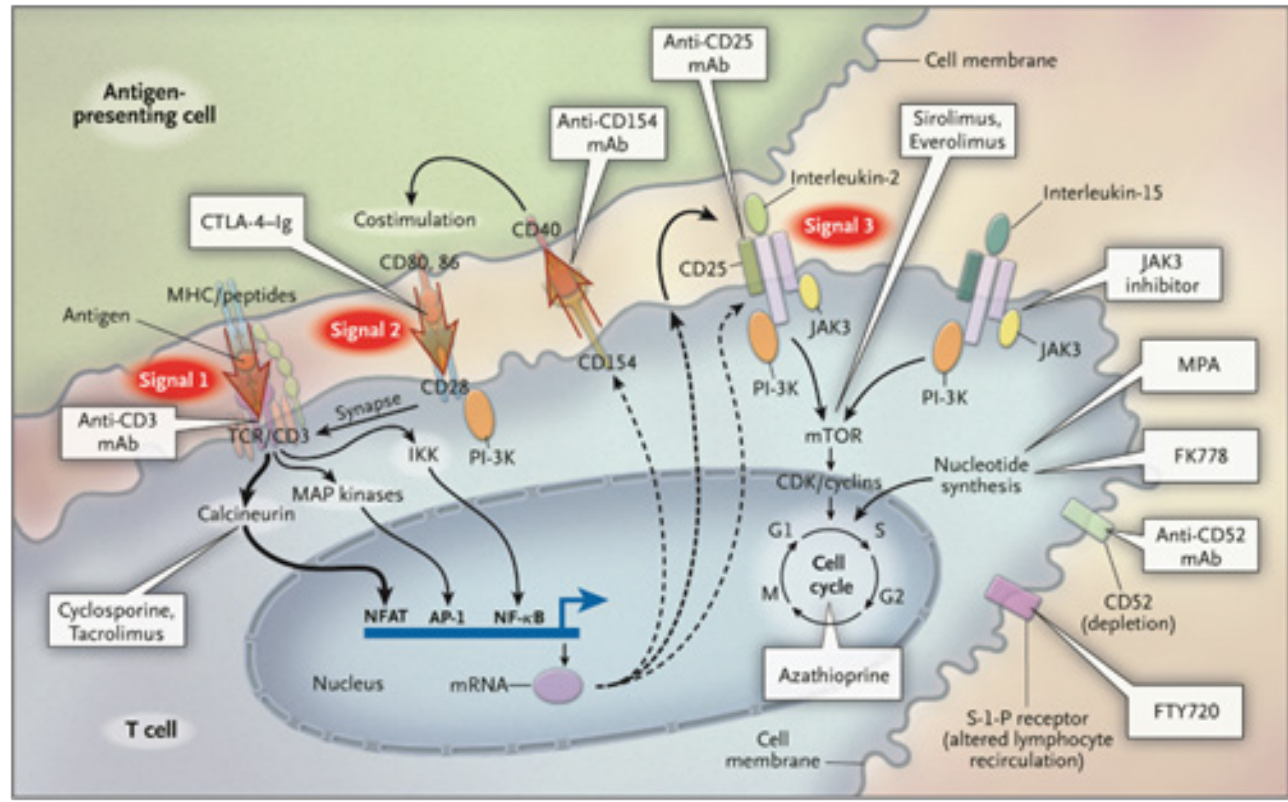

Figure I The All immune response requires activation of multiple signaling pathways. 
Rejection takes place by cellular and antibody-mediated processes. ${ }^{30-33}$ In cellular rejection (CMR), effector $\mathrm{T}$ cells mediate an inflammatory response leading to infiltration of the myocardium by activated macrophages, effector $\mathrm{T}$ cells, and plasma cells. The characteristic lesion of CMR consists of mononuclear cells invading the myocardium. CMR is classified into 3 grades depending on the extent of cellular infiltration and myocyte damage. In the internationally accepted grading system for cellular rejection, ISHLT grade $2 \mathrm{R}$ or higher is considered clinically significant cellular rejection. ${ }^{34,35}$ Antibody-mediated rejection (AMR) occurs when alloantibody against donor antigens targets capillary endothelium. ${ }^{31-33}$ AMR is usually associated with hemodynamic compromise at presentation and a greater risk of allograft vasculopathy and mortality. ${ }^{32,33}$ AMR is usually diagnosed histologically by demonstration of capillary injury with endothelial cell swelling and intravascular macrophage accumulation. Positive immuno fluorescence for CD 68, C4d and C3d complement fragments may be associated with clinical allograft dysfunction. ${ }^{35,36}$

\section{Advances in immunosuppression}

The success of heart transplantation was closely related to the discovery of effective immunosuppressive regimens. In the early 1980s, the introduction of cyclosporine was followed by a significant improvement in survival of heart transplant recipients Immunosuppression prevents or treats rejection and minimizes the risk of infection or malignancy. Immunosuppression may block lymphocyte activation or response pathways, or by depleting lymphocytes, or diverting lymphocytic traffic. ${ }^{26,37}$ Induction therapy is a period of intense immunosuppression in the initial days after transplantation. This provides intensive immunosuppression when the alloimmune response is also most intense. It may also be used to permit delayed initiation of calcineurin inhibitors (CNIs) in patients with significant renal failure. Induction immunosuppression may use depleting antibodies \{e.g., polyclonal antibodies (horse or rabbit anti thymocyte globulin), anti-CD3 antibodies (OKT3), human monoclonal anti-CD52 (alentuzumab)\}, or nondepleting antibodies (e.g., anti-CD25 antibodies (daclizumab, basiliximab) or fusion proteins \{e.g., CTLA4-Ig (LEA29Y)\}. ${ }^{38-40}$

A survival benefit of induction therapy not been clearly established, however. ${ }^{38-40}$ OKT3 use may be associated with a greater risk of lymphoproliferative disorders. ${ }^{38,41}$ Induction agents are probably most useful in highly sensitized patients or patients with severe RF at the time of transplantation. Maintenance immunosuppression is usually triple therapy, comprising corticosteroids (usually prednisolone), a CNI (cyclosporine or tacrolimus), and an anti proliferative agent (usually mycophenolate mofetil). Prednisolone is used early after heart transplantation and tapered to low doses or withdrawn during the first year. Withdrawal of steroids may take place early within the first month after or later between 6 to 12 months post-transplant. Late steroid withdrawal may have the advantage of maintaining more intensive therapy in the first 6months when the risk of rejection is still high. ${ }^{41-43}$ There is a strong interest in minimising steroid use in children, as it impairs growth. ${ }^{9}$ Tacrolimus is the most commonly used CNI. ${ }^{5,44}$ It is associated with a decreased incidence of rejection episodes and is used instead of cyclosporine where rejection is more likely. ${ }^{45}$ Tacrolimus may be used as monotherapy in heart transplantation and has shown to be safe. ${ }^{44}$ Mycophenolate mofetil has replaced the use of azathioprine. Molecular target of rapamycin inhibitors or proliferation signal inhibitors (sirolimus and everolimus) may decrease the progression of allograft vasculopathy and cancer as well as provide resistance to rejection. ${ }^{46-48}$ Poor wound healing is a serious side effect associated with sirolimus and everolimus and limits its use early post-transplant. ${ }^{48}$

In patients with allograft vasculopathy, sirolimus may limit progression and lead to reversal of the process. ${ }^{47-50}$ In patients with severe renal failure (RF), calcineurin-free regimens (combining sirolimus and mycophenolate mofetil) late after transplantation can improve renal function without increasing the risk of rejection. ${ }^{51,52}$ Belatacept, a co stimulatory signal inhibitor could represent an alternative to CNIs. ${ }^{53}$ In de-novo renal transplant recipients, there was no significant difference in acute rejection rates between belatacept and cyclosporine..$^{53}$ Belatacept resulted in significantly lower rates of tubular atrophy and interstitial fibrosis. If proven efficacious and safe in renal transplantation, Belatacept will undergo investigation in heart transplantation. Individualization of immunosuppression with better immune monitoring and pharmacogenomics will eventually plays a greater role in optimization of therapy. ${ }^{54}$

The Methods for managing acute rejection are evolving. The management of acute rejection depends on the histological type of rejection (cellular vs. AMR) as well as its severity (hemodynamic compromise and/or high histological grade) and history of prior immunosuppression and rejection episodes. A high-dose corticosteroid (3-day course of methylprednisolone $1 \mathrm{~g}$ daily) is used for significant cellular rejection ( $>2 \mathrm{R}$ ISHLT classification) or any rejection-associated hemodynamic compromise. Lymphocytedepleting agents such as antithymocyte globulin are also considered in patients with hemodynamically compromising or high-grade (3R) cellular rejection..$^{55}$ Studies assessing the best treatment strategy for AMR are currently in progress. ${ }^{33}$ Severe AMR with hemodynamic compromise is usually treated with high-dose corticosteroids and Plasmapheresis followed by intravenous immunoglobulin or rituximab (B-cell depleting monoclonal anti-CD20 antibody). T cell depleting antibodies such as antithymocyte globulin are sometimes added to help modulate the interaction of $\mathrm{T}$ and $\mathrm{B}$ cells. Recurrent rejection is challenging to manage. Options include photo pheresis and total lymphoid irradiation. ${ }^{56-58}$ Total lymphoid irradiation has been shown to decrease the chances of subsequent rejection but may be associated with a greater risk of lymph proliferative disorders. ${ }^{58}$

\section{Transplantation across blood groups}

Transplantation of hearts from ABO-incompatible donors is contraindicated because of the risk of hyper acute rejection mediated by preformed antibodies in the recipient to blood-group antigens of the donor. This contraindication may not apply to newborn infants, who do not yet produce antibodies to T-cell-independent antigens, including the major blood-group antigens. In particular, stimulation by T-cell-independent polysaccharide antigens, such as the capsular components of bacteria (e.g., pneumococcal), does not elicit a serum antibody response early in life. ${ }^{59}$ Similarly, the production of antibodies to the carbohydrate blood-group antigens begins at the age of six to eightmonths, in infants of susceptible genotypes, as a cross-reactive immune response after the colonization of the gut with polysaccharide-bearing Escherichia coli. ${ }^{59}$

When ABO incompatible transplantation is performed, serum is hem agglutinin titers are measured before and after the transplant. Plasmapheresis, immuno adsorption or administration of soluble carbohydrate antigen is used, as well as plasma exchange during cardiopulmonary bypass as the transplant operation is taking place. Standard immunosuppressive therapy is used and rejection is 
monitored by endomyocardial biopsy. There is usually no damage to the graft, despite the eventual development of antibodies to antigens of the donor's blood group in some infants. The absence of antibody production or its delay beyond the time expected because of early immunosuppression, may be evidence of partial B-cell tolerance induced by exposure to donor antigens during the maturation of the immune system. ${ }^{59,60}$ It is also thought that accommodation occurs. This term originally describes endothelial cell resistance to antibodymediated rejection after ABO-incompatible kidney or experimental xenograft transplant. ${ }^{33}$ The use of $\mathrm{ABO}$-incompatible donors has resulted in the mortality rate among infants on the waiting list declining from 58 percent to 7 percent.

\section{Donor specific alloreactivity}

Hyper acute and delayed antibody-mediated rejection has devastating effects and may result in graft loss. It is mandatory to avoid situations where antibody-mediated rejection may occur Recipients are screened for antibodies that react with lymphocytes from a panel representative of the major HLA allotypes (PRAs). High PRA levels indicate sensitization to various alloantigens and the risk of donor specific alloreactivity. These patients require donor-specific T-cell cross-matches before transplantation to exclude the presence of lymphocytotoxic IgG antibodies against donor class I HLAs, which can cause early graft failure resulting from complement-mediated humoral rejection. ${ }^{61,62} \mathrm{~A}$ positive donor-specific T-cell cross-match is a contraindication to transplantation. Sensitized candidates have longer waiting times and higher mortality rates while waiting. ${ }^{61,62}$ The presence of preformed anti-HLA antibodies predicts an increased number of cellular rejection episodes, earlier coronary allograft vasculopathy $(\mathrm{CAV})$ onset, and decreased long-term graft survival. ${ }^{61}$ These complications are related to the presence of preformed antibodies against allogeneic HLA class II molecules. There may be an underlying state of CD4 T-cell allo-sensitisation to class II antigens in sensitized candidates. ${ }^{63-65}$

The proportion of highly sensitized patients on cardiac transplant waiting lists has increased as a result of widespread use of left ventricular assist devices (LVADs) ${ }^{66}$ and more patients undergoing retransplantation ${ }^{67}$. Whereas alloreactivity in retransplant candidates, blood product recipients, and multiparous women is a result of repeated B- and T-cell exposure to alloantigen, the high frequency of alloreactivity in LVAD recipients seems to result additionally from polyclonal B-cell activation. ${ }^{68,69}$ LVAD recipients are usually treated with induction immunosuppression. Interventions in sensitized recipients usually result in Ig depletion and B-cell suppression. Pooled human intravenous Ig is effective in reducing allo-sensitisation. ${ }^{70,71}$ This may be due to the presence, in intravenous Ig, of anti-idiotypic antibodies, ${ }^{72,73}$ antibodies against membrane-associated immunologic molecules such as CD4 or CD5, ${ }^{74,75}$ or soluble forms of HLA molecules. ${ }^{76,77}$ Serum reactivity to HLA class I molecules in LVAD recipients may be reduced with intravenous Ig or Plasmapheresis. ${ }^{78-82}$ Alternative modalities for alloreactive antibody reduction include immunoadsorption, rituximab and cyclophosphamide. ${ }^{83,84}$ Intravenous pulse cyclophosphamide therapy, together with pre transplantation intravenous Ig as part of a $\mathrm{CyA} /$ steroid-based regimen in sensitized cardiac allograft recipients, is extremely effective and safe for decreasing recipient serum and cellular alloreactivity, shortening transplant waiting time, and reducing allograft rejection.

\section{Post-transplant monitoring}

Immune monitoring of cardiac transplants currently relies on endomyocardial biopsy, drug level monitoring, and echocardiography. Many patients still present with rejection, infection, or drug toxicity despite having the desired level of immunosuppression. Endomyocardial biopsy is the gold standard for the diagnosis of rejection and has been so for manyyears. It is limited by significant sampling error and inter-observer variability. There is also variability in frequency and duration of surveillance endomyocardial biopsy, with most centres now limit routine endomyocardial biopsies to $<5$ years. ${ }^{85}$ Cellular rejection may result in abnormal diastolic parameters of allograft function. ${ }^{86,87}$ A $10 \%$ change in maximal systolic or diastolic tissue Doppler velocity of the posterior wall of the left ventricle is a sensitive and specific marker of cellular rejection (grade $>2$ in the previous classification). Elevation in BNP is associated with cellular rejection. ${ }^{88}$ Therapeutic monitoring of drug is very useful in the posttransplant surveillance period with CNIs monitored closely at $\mathrm{C} 0$ and now at $\mathrm{C} 2$ intervals. ${ }^{89-91}$

Gene expression profiling (GEP) is useful in identifying rejection. ${ }^{92-94}$ Genes activated during acute cellular rejection include those involved in the pathways of $\mathrm{T}$ cell activation, natural killercell activation, stem cell mobilization, hematopoiesis, alloimmune recognition, and steroid responsiveness. In the Cardiac Allograft Rejection Gene Expression Observation study, an algorithm was developed and validated based on the expression of 20 genes. ${ }^{92,94}$ The algorithm weighs the contribution of each gene and generates a score from 0 to 40 . Scores below threshold indicate a very low likelihood of moderate-to-severe acute cellular rejection on endomyocardial biopsy (ISHLT grade $>3 \mathrm{~A} / 2 \mathrm{R}$ ). Further information is needed to assess the safety of routine GEP instead of biopsies before GEP is widely adopted clinically. ${ }^{94}$ There are direct immune assays that monitor antibody production and $\mathrm{T}$ cell function to assist in the recognition of rejection. ${ }^{6,94-97}$ Anti-HLA donor-specific antibodies are associated with an increased incidence of early and severe allograft rejection and with the late development of cardiac allograft vasculopathy and decreased survival. ${ }^{6,98,99}$ The importance of non-HLA antibodies is also being increasingly recognized. ${ }^{6}$ Comprehensive monitoring will rely, in future, on a combination of biopsy with histopathology, graft functional monitoring with imaging modalities and B-type natriuretic peptide (BNP), drug level monitoring, GEP, monitoring of donorspecific antibodies, and direct immune function assays.

\section{Long term complications of heart transplantation}

Transplant vasculopathy and malignancy are the 2 most important causes of death after 1 year. ${ }^{5}$ Significant allograft vasculopathy is found in approximately $30 \%$ to $50 \%$ of patients at 5 years. ${ }^{5,7}$ It is characterized by diffuse intimal hyperplasia affecting the epicardial vessels and the microcirculation in a longitudinal and concentric fashion and plaque rupture is rare. ${ }^{7,100-102}$ Non-immune risk factors for allograft vasculopathy include hyperlipidemia, hypertension, diabetes mellitus, homocysteinemia, older donor age, and donor brain stem death. ${ }^{5,103,104}$ Immune risk factors are HLA donor/recipient mismatches (especially HLA DR Mismatches), recurrent cellular rejection, AMR and cytomegalovirus. ${ }^{32,87,103-105}$.

Intravascular ultrasound is very useful in the diagnosis and followup of allograft vasculopathy. ${ }^{104,106}$ Intimal thickness progression of more than $0.5 \mathrm{~mm}$ during the first year is a powerful predictor of mortality, myocardial infarction, and later coronary artery disease. ${ }^{106}$ Management focuses on the aggressive management of risk factors, particularly hyperlipidemia and the use of proliferation signal inhibitors such as sirolimus. ${ }^{48,107}$ Statin therapy has also been recently shown to have sustained survival benefits with a decrease 
in allograft vasculopathy. ${ }^{108,109}$ Percutaneous revascularization of allograft vasculopathy may be done for focal lesions, but the benefits of the procedure are limited by the diffuse nature of the disease. ${ }^{110}$ Re-transplantation is also considered in selected patients with severe allograft vasculopathy. Post transplant lymphoproliferative disorder (PTLD) and skin cancers are the common malignancies seen after transplantation. Risks for PTLD include aggressive immunosuppression, OKT3 use young age and Epstein-Barr virus seronegative recipients, especially with a seropositive donor. ${ }^{111,112}$ Proliferation signal inhibitors have anti tumour properties and may even lead to the regression of some malignancies, and rituximabis an effective treatment for PTLD. ${ }^{111,112}$

\section{Tolerance induction}

The induction of specific tolerance to donor antigens remains the ultimate goal in transplantation medicine. Specific tolerance would also retain the remaining immune repertoire to deal with infection and malignancy. Effective donor tolerance may be produced experimentally by bone marrow transplantation into recipients conditioned with co stimulatory blockade (anti CTLA4-Ig), resulting in chimerism. A clinical trial is underway to investigate this possible treatment (Bone Marrow Transplant to Induce Tolerance in Heart Transplant Recipients). Heart transplantation usually involves no HLA matching, so such induction of chimerism would require potentablation of the recipient bone marrow, significant radiation exposure, and ongoing immunosuppression. ${ }^{113,114}$

\section{Conclusion}

Heart transplantation is evolving and now has excellent long term outcomes. It is the ideal solution for intractable end stage heart failure in eligible patients. Improvements in our understanding the alloimmune activation response and its pathways have led to the development of new immunosuppressive agents and better regimens. In the future, advances in immunosuppression and the use of more specific monitoring tools are likely to lead to significant improvements in outcomes. With ongoing research in the scientific and clinical communities, it is hoped that transplant physicians would have the tools to induce immune tolerance, greatly improving outcomes further.

\section{Acknowledgement}

None.

\section{Conflicts of interest}

Authors declare that there is no conflict.

\section{Funding}

None.

\section{References}

1. McRae D. Every second counts: the race to transplant the first human heart. NY: G.P. Putnam's Sons, New York; 2006. pp. 356.

2. Ventura HO, Muhammed K. Historical perspectives on cardiac transplantation:the past as prologue to challenges for the 21 st century. Curr Opin Cardiol. 2001;16(2):118-123.

3. Hunt SA. Taking heart-cardiac transplantation past, present, andfuture. $N$ Engl J Med. 2006;355(3):231-235.

4. Cooper MA, Pommering TL, Koranyi K. Primary immunodeficiencies. Am Fam Physician. 2003;68(10):2001-2008.
5. Lund LH, Edwards LB, Kucheryavaya AY, et al. Registry of the International Society for Heart and Lung Transplantation:thirtieeth official adult heart transplant report-2013; focus theme: age. J Heart Lung Transplant. 2003;32(10):951-964.

6. Aliabadi AZ, Zuckermann AO, Grimm M. Immunosuppressive therapy in older cardiac transplant patients. Drugs Aging. 2007;24(11):913-932.

7. Valantine H. Cardiac allograft vasculopathy after heart transplantation:Risk factors and management. J Heart Lung Transplant. 2004;23(5 Suppl):S187-S193.

8. Hosseinpour AR, Cullen S, Tsang VT. Transplantation for adults with congenital heart disease. Eur J Cardiothorac Surg. 2006;30(3):508-514.

9. Alkhaldi A, Chin C, Bernstein D. Pediatric cardiac transplantation. Semin Pediatr Surg. 2006;15(3):188-198.

10. Kerman RH. Understanding the sensitised patient. Heart Fail Clin. 2007;3(1):1-9.

11. Hunt SA. Mechanical circulatory support:new data, old problems. Circulation. 2007;116(5):461-462.

12. Johnson MR, Aaronson KD, Canter CE, et al. Heart retransplantation. Am J Transplant. 2007;7(9):2075-2081.

13. Magee JC, Barr ML, Basadonna GP, et al.Repeat organ transplantationin the United States, 1996-2005. Am J Transplant. 2007;7(5 pt 2):14241433 .

14. John R, Chen JM, Weinberg A, et al. Long-term survival after cardiac retransplantation: a twenty-year single center experience. J Thorac Cardiovasc Surg. 1999;117(3):543-555.

15. Aaronson KD, Schwartz JS, Chen TM, et al. Development and prospective validation of a clinical index to predict survival in ambulatory patients referred for cardiac transplant evaluation. Circulation. 1977;95(12):2660-2667.

16. Mehra MR, Kobashigawa J, Starling R, et al. Listing criteria for heart transplantation:International Society for Heart and Lung Transplantation guidelines for the care of cardiac transplant candidates:2006. J Heart Lung Transplant. 2006;25(9):1024-1042.

17. Christie JD, Edwards LB, Kucheryavaya AY, et al. The Registry of the International Society for Heart and Lung Transplantation:Twenty seventh official adult lung and heart and lung transplant report 2010. J Heart Lung Transplant. 2010;29(10):1104-1118.

18. Renlund DG, Taylor DO, Kfoury AG, et al. New UNOS rules:Historical background and implications for transplantation management. United Network for Organ Sharing. J Heart Lung Transplant. 1999;18(11):10651070 .

19. McCarthy PM, Quader MA, Hoercher KJ. Evolving strategies for surgical management of patients with severe left ventricular dysfunction. Heart Lung Circ. 2003;12(1):31-38.

20. Rodeheffer RJ, Naftel DC, Stevenson LW, et al. Secular trends in cardiac transplant recipient and donor management in the United States, 1990 to 1994. A multi-institutional study. Cardiac Transplant Research Database Group. Circulation. 1966;94(11):2883-2889.

21. West LJ, Pollock BarZiv SM, Dipchand AI, et al. ABO-incompatible heart transplantation in infants. N Engl J Med. 2001;344(11):793-800.

22. Kuppahally SS, Valantine HA, Weisshaar D, et al. Outcome in cardiac recipients of donor hearts with increased left ventricular wall thickness. Am J Transplant. 2007;7(10):2388-2395.

23. Gasink LB, Blumberg EA, Localio AR, et al. Hepatitis C virus seropositivity in organ donors and survival in heart transplant recipients. JAMA. 2006;296(15):1843-1850. 
24. Uriel N, Jorde UP, Cotarlan V, et al. Heart transplantation in human immunodeficiency virus-positive patients. J Heart Lung Transplant. 2009;28(7):667-669.

25. Boyarsky BJ, Hall EC, Singer AL, et al. Estimating the potential pool of HIV-infected deceased organ donors in the United States. Am J Transplant. 2011;11(6):1209-1217.

26. Liu Z, Colovai AI, Tugulea S, et al. Indirect recognition of donor HLADR peptides in organ allograft rejection. J Clin Invest. 1996;98(5):1150 1157.

27. Halloran PF. Immunosuppressive drugs for kidney transplantation. $N$ Engl J Med. 2004;351(26):2715-2729.

28. Von Andrian UH, Mackay CR. T-cell function and migration. Two sides of the same coin. $N$ Engl J Med. 2000;343(14):1020-1034.

29. Biedermann BC, Pober JS. Human endothelial cells induce andregulate cytolytic T cell differentiation. J Immunol. 1988;161(9):4679-4687.

30. Wang D, Matsumoto R, You Y, et al. CD3/CD28 costimulation-induced $\mathrm{NF}$-kappaB activation is mediated by recruitment of protein kinase $\mathrm{C}$ theta, Bcl10, and IkappaB kinase beta to the immunological synapse through CARMA1. Mol Cell Biol. 2004;24(1):164-171.

31. Hammond EH, Yowell RL, Nunoda S, et al. Vascular (humoral) rejection in heart transplantation:pathologic observations and clinical implications. $J$ Heart Transplant. 1989;8(6):430-443.

32. Michaels PJ, Fishbein MC, Colvin RB. Humoral rejection of humanorgan transplants. Springer Semin Immunopathol. 2003;25(2):119-140.

33. Uber WE, SelfSE, Van BakelAB, et al. Acute antibody-mediated rejection following heart transplantation. Am J Transplant. 2007;7(9):2064-2074.

34. Bernstein D, Williams GE, Eisen $\mathrm{H}$, et al. Gene expression profiling distinguishes a molecular signature for grade 1B mild acute cellular rejection in cardiac allograft recipients. J Heart Lung Transplant. 2007;26(12):1270-1280.

35. Stewart S, Winters GL, Fishbein MC, et al. Revision of the 1990 working formulation for the standardization of nomenclature in the diagnosis of heart rejection. J Heart Lung Transplant. 2005;24(11):1710-1720.

36. Rodriguez ER, Skojec DV, Tan CD, et al. Antibody-mediated rejection in human cardiac allografts:evaluation of immunoglobulins and complement activation products $\mathrm{C} 4 \mathrm{~d}$ and $\mathrm{C} 3 \mathrm{~d}$ as markers. $\mathrm{Am} J$ Transplant. 2005;5(11):2778-2785.

37. Yabu JM, Vincenti F. Novel immunosuppression:small molecules and biologics. Semin Nephrol. 2007;27(4):479-486.

38. Baran DA. Induction therapy in cardiac transplantation:when and why? Heart Fail Clin. 2007;3(1):31-41.

39. Hershberger RE, Starling RC, Eisen HJ, et al. Daclizumab to prevent rejection after cardiac transplantation. NEngl JMed. 2005;352(26):27052713.

40. Carrier M, White M, Perrault LP, et al. A 10year experience within travenous thymoglobuline in induction of immunosuppression following heart transplantation. J Heart Lung Transplant. 1999;18(12):1218-1223.

41. Everly MJ, Bloom RD, Tsai DE, et al. Post transplant lymphoproliferative disorder. Ann Pharmacother. 2007;41(11):1850-1858.

42. Kobashigawa JA, Stevenson LW, Brownfield ED, et al. Initial success of steroid weaning late after heart transplantation. J Heart Lung Transplant. 1992;11(2 Pt 2):428-430.

43. Miller LW, Wolford T, McBride LR, et al. Successful withdrawal of corticosteroids in heart transplantation. J Heart Lung Transplant. 1992;11(2 Pt 2):431-434.

44. Lubitz SA, Baran DA, Alwarshetty MM, et al. Long term results of tacrolimus monotherapy in cardiac transplant recipients. J Heart Lung Transplant. 2006;25(6):699-706.
45. Kobashigawa JA, Miller LW, Russell SDet al. Tacrolimus with mycophenolate mofetil (MMF) or sirolimus vs. cyclosporine with MMF in cardiac transplant patients:1-year report. Am J Transplant. 2006;6(6):1377-1386.

46. Eisen HJ. Immunosuppression on the horizon. Heart Fail Clin 2007;3(1):43-49.

47. Mancini D, Pinney S, Burkhoff D, et al. Use of rapamycin slows progression of cardiac transplantation vasculopathy. Circulation. 2003;108(1):48-53.

48. Valantine H. Prevention of cardiac allograft vasculopathy with Certican (everolimus):the Stanford University experience within the Certican Phase III clinical trial. J Heart Lung Transplant. 2005;24(4 Suppl):S191S195.

49. Kuppahally S, Al-Khaldi A, Weisshaar D, et al. Wound healing complications with de novo sirolimus versus mycophenolate mofetilbased regimen in cardiac transplant recipients. Am J Transplant. 2006;6(5 Pt 1):986-992.

50. Raichlin E, Khalpey Z, Kremers W, et al. Replacement of calcineurininhibitors with sirolimus as primary immunosuppression in stable cardiac transplant recipients. Transplantation. 2007;84(4):467-474.

51. Bestetti R, Theodoropoulos TA, Burdmann EA, et al. Switch from calcineurin inhibitors to sirolimus-induced renal recovery in heart transplant recipients in the midterm follow-up. Transplantation. 2006;81(5):692-696.

52. Cantarovich M. Renal protective strategies in heart transplant patients Curr Opin Cardiol. 2007;22(2):133-138.

53. Vincenti F, Larsen C, Durrbach A, et al. Costimulation blockade with belatacept in renal transplantation. N Engl J Med. 2005;353(8):770-781.

54. Macphee IA, Fredericks S, Tai T, et al. Tacrolimus pharmacogenetics :polymorphisms associated with expression of cytochrome p450-3A5and P-glycoprotein correlate with dose requirement. Transplantation. 2002;74(11):1486-1489.

55. Marboe CC, Billingham M, Eisen $\mathrm{H}$, et al. Nodular endocardial infiltrates (Quilty lesions) cause significant variability in diagnosis of ISHLT grade 2 and $3 \mathrm{~A}$ rejection in cardiac allograft recipients. J Heart Lung Transplant. 2005;24(7 Suppl):S219-S226.

56. Kirklin JK, Brown RN, Huang ST, et al. Rejection with hemodynamic compromise:objective evidence for efficacy of photopheresis. J Heart Lung Transplant. 2006;25(3):283-288.

57. Frist WH, Biggs VJ. Chronic myelogenous leukemia after lymphoid irradiation and heart transplantation. Ann Thorac Surg.1994;57(1):214 216

58. Urschel S, Larsen IM, Kirk $\mathrm{R}$, et al. ABO-incompatible heart transplantation in early childhood:an international multicenter study of clinical experiences and limits. $J$ Heart Lung Transplant. 2013;32(3):285-292.

59. Irving C, Gennery A, Kirk R. Pushing the boundaries:the current status of ABO-incompatible cardiac transplantation. J Heart Lung Transplant. 2012;31(8):791-796

60. Smith JD, Danskine AJ, Laylor RM, et al. The effect of panel reactive antibodies and the donor specific crossmatch on graft survival after heart and heart-lung transplantation. Transpl Immunol. 1933;1(1):60-65.

61. Ratkovec RM, Hammond EH, O'Connell JB, et al. Outcome of cardiac transplant recipients with a positive donor-specific crossmatch - preliminary results with plasmapheresis. Transplantation. 1922;54(4):651-655

62. Itescu S, Tung T, Burke E, et al. Preformed IgG antibodies against major histocompatibility class II antigens are major risk factors for high-grade cellular rejection in recipients of heart transplantation. Circulation. 1988;98(8):786-793. 
63. Tugulea S, Ciubotariu R, Colovai AI, et al. New strategies for early diagnosis of heart allograft rejection. Transplantation. 1977;64(6):842847.

64. Ciubotariu R, Liu Z, Colovai AI, et al. Persistent allopeptide reactivity and epitope spreading in chronic rejection of organ allografts. J Clin Invest. 1977;101(2):398-405.

65. Vanderlugt CJ, Miller SD. Epitope spreading. Curr Opin Immunol. 1966;8(6):831-836.

66. John R, Lietz $\mathrm{K}$, Naka $\mathrm{Y}$, et al. Immunologic sensitization in recipients of left ventricular assist devices. J Thorac Cardiovasc Surg. 2003;125(3):578-591.

67. John R, Chen JM, Weinberg A, et al. Long-term survival after cardiac retransplantation:a twenty-year single center experience. J Thorac Cardiovasc Surg. 1999;117(3):543-555.

68. Mamula MJ, Janeway CA Jr. Do B cells drive the diversification of immune responses? Immunol Today. 1933;14(4):151-154.

69. Reed EF, Hong B, Ho E, et al. Monitoring of soluble HLA alloantigen and anti- HLA antibodies identifies heart allograft recipients at risk of transplant associated coronary artery disease. Transplantation. 1966;61(4):556-572.

70. Glotz D, Haymann J, Sansonetti N, et al. Suppression of HLA-specific alloantibodies by high-dose intravenous immunoglobulins (IVIg). Transplantation. 1933;56(2):335-337.

71. Tyan TB, Li VA, Czer L, Trento A, et al. Intravenous immunoglobulin suppression of HLA alloantibody in highly sensitized transplan candidates and transplantation with a histo-incompatible organ. Transplantation. 1994;57(4):553-562.

72. Dietrich G, Algiman M, Sultan Y, et al. Origin of anti-idiotypic activity against antifactor VIII autoantibodies in pools of normal human immunoglobulin G (IVIg). Blood. 1922;79(11):2946-2951.

73. Rossi F, Kazatchkine MD. Antiidiotypes against autoantibodies in pooled normal human polyspecific Ig. J Immunol. 1989;143(12):4104-4109.

74. Hurez V, Kaveri SV, Mouhoub A, et al. Anti-CD4 activity of norma human immunoglobulins for therapeutic use (IVIg). Ther Immunol. 1933;1(5):269-278.

75. Vassilev T, Gelin C, Kaveri SV, et al. Antibodies to the CD5 molecule in normal human immunoglobulins for therapeutic use (IVIg). Clin Exp Immunol. 1933;92(3):369-372.

76. Blasczyk R, Westhoff U, Grossewilde H. Soluble CD4, CD8, and HLA molecules in commercial immunoglobulin preparations. Lancet. 1933;341(8848):789-790.

77. Lam L, Whitsett CF, McNicholl JM, et al. Immunologically active proteins in intravenous immunoglobulin. Lancet.1933;342(8872):678.

78. John R, Lietz K, Burke E, et al. Intravenous immunoglobulin reduces antiHLA alloreactivity and shortens waiting time to cardiac transplantation in highly sensitized left ventricular assist device recipients. Circulation 1999;100(19 Supp1):II229-II235

79. John R, Lietz K, Naka Y, et al. Immunologic sensitization in recipients of left ventricular assist devices. J Thorac Cardiovasc Surg. 2003;125(3):578-591.

80. Glotz D, Haymann JP, Sansonetti N, et al. Suppression of HLA-specific alloantibodies by high-dose intravenous immunoglobulins (IVIg). A potential tool for transplantation of immunized patients. Transplantation. 1933;56(2):335-337.

81. Tyan TB, Li VA, Czer L, et al. Intravenous immunoglobulin suppression of HLA alloantibody in highly sensitized transplant candidates and transplantation with a histo-incompatible organ. Transplantation. 1994;57(4):553-562.
82. McIntyre JA, Higgins N, Britton R, et al. Utilization of intravenous immunoglobulin to ameliorate alloantibodies in a highly sensitized patient with a cardiac assist device awaiting cardiac transplantation. Transplantation. 966;62(5):691-693.

83. De Marco T, Damon LE, Colombe B, et al. Successful immunomodulation with intravenous immunoglobulin and cyclophosphamide in an alloimmunized heart transplant recipient. $J$ Heart Lung Transplant. 1977;16(3):360-365.

84. Itescu S, Burke E, Lietz $\mathrm{K}$, et al. Intravenous pulse administration of cyclophosphamide is an effective and safe treatment for sensitized cardiac allograft recipients. Circulation. 2002;105(10):1214-1219.

85. Stehlik J, Starling RC, Movsesian MA, et al. Utility of longtermsurveillance endomyocardial biopsy:a multi-institutionalanalysis. $J$ Heart Lung Transplant. 2006;25(12):1402-1409.

86. Dandel M, Hummel M, Muller J, et al. Reliability of tissue Doppler wall motion monitoring after heart transplantation for replacement of invasive routine screenings by optimally timed cardiac biopsies and catheterizations. Circulation. 2001;104(12 Suppl 1):I184-1191.

87. Valantine HA, Fowler MB, Hunt SA, et al. Changes in Doppler echocardiographic indexes of left ventricular function as potential markers of acute cardiac rejection. Circulation. 1987;76(5 Pt 2):V86V92.

88. Martinez-Dolz L, Almenar L, Moro J, et al. Prognostic value of brain natriuretic peptide in heart transplant patients. J Heart Lung Transplant. 2007;26(10):986-991.

89. Diciolla F, Scolletta $\mathrm{S}$, Berti $\mathrm{L}$, et al. $\mathrm{C}_{2}$ and $\mathrm{C}_{0}$ values for monitoring cyclosporine therapy in stable heart transplant recipients. Transplant Proc. 2005;37(2):1355-1359.

90. Mardigyan V, Giannetti N, Cecere R, et al. Best single time points to predict the area-under-the-curve in long-term heart transplant patients taking mycophenolate mofetil in combination with cyclosporine or tacrolimus. J Heart Lung Transplant. 2005; 24(10):1614-1618.

91. Aumente Rubio MD, Arizon del Prado JM, Lopez Malo de Molina MD, Cárdenas Aranzana M, Segura Saint-Gerons J, et al. (2003) Clinical pharmacokinetics of tacrolimus in heart transplantation:new strategies of monitoring. Transplant Proc 35(5):1988-1991.

92. Deng MC, Eisen HJ, Mehra MR, et al. Noninvasive discrimination ofrejection in cardiac allograft recipients using gene expression profiling. Am J Transplant. 2006;6(1):150-160.

93. Mehra MR, Uber PA. Genomic biomarkers and heart transplantation. Heart Fail Clin. 2007;3(1):83-86.

94. Pham MX, Deng MC, Kfoury AG, et al. Molecular testing for long-term rejection surveillance in heart transplant recipients:design of the Invasive Monitoring Attenuation Through Gene Expression (IMAGE) trial. $J$ Heart Lung Transplant. 2007;26(8):808-814

95. Kowalski R, Post D, Schneider MC, et al. Immune cell function testing:an adjunct to therapeutic drug monitoring in transplant patient management. Clin Transplant. 2003;17(2):77-88.

96. Newell KA, Larsen CP. Tolerance assays:measuring the unknown Transplantation. 2006;81(11):1503-1509.

97. Kobashigawa J. Immune function in adult heart transplant patients reflects risk for organ rejection and infection. Paper presented at: International Society for Heart and Lung Transplantation Meeting. Boston: MA; 2008

98. Girlanda R, Mannon RB, Kirk AD. Diagnostic tools for monitoring kidney transplant recipients. Semin Nephrol. 2007;27(4):462-478.

99. Rose EA, Pepino P, Barr ML, et al. Relation of HLA antibodies and graft atherosclerosis in human cardiac allograft recipients. J Heart Lung Transplant. 1992;11(3 Pt 2):S120-S123. 
100. Zerbe TR, Kormos R, Arena V, et al. Histocompatibility and other rejection risk factors in cardiac transplantation. Transplant Proc. 1991;23(1 PT 2):1155-1156.

101. Gao SZ, Alderman EL, Schroeder JS, et al. Progressive coronary luminal narrowing after cardiac transplantation. Circulation. 1990;82(5 Suppl):IV269-IV275.

102. Mitchell RN, Libby P. Vascular remodeling in transplant vasculopathy. Circ Res. 2007;100(7):967-978.

103. Rahmani M, Cruz RP, Granville DJ, et al. Allograft vasculopathy versus atherosclerosis. Circ Res. 2006;99(8):801-815.

104. Costanzo MR, Naftel DC, Pritzker MR, et al. Heart transplantcoronary artery disease detected by coronary angiography: a multi institutional study of preoperative donor and recipient risk factors. Cardiac Transplant Research Database. J Heart Lung Transplant. 1988;17(8):744-753.

105. Sipahi I, Starling RC. Cardiac allograft vasculopathy:an update. Heart Fail Clin. 2007;3(1):87-95.

106. Valantine HA. The role of viruses in cardiac allograft vasculopathy. Am J Transplant. 2004;4(2):169-177.

107. Tuzcu EM, Kapadia SR, Sachar R, et al. Intravascular ultrasound evidence of angiographically silent progression in coronary atherosclerosis predicts long-term morbidity and mortality after cardiac transplantation J Am Coll Cardiol. 2005;45(9):1538-1542.
108. Raichlin E, Bae JH, Khalpey Z, et al. Conversion to sirolimus as primary immunosuppression attenuates the progression of allograft vasculopathy after cardiac transplantation. Circulation. 2007;116(23):2726-2733.

109. Kobashigawa JA, Katznelson S, Laks H, et al. Effect of pravastatin on outcomes after cardiac transplantation. N Engl J Med. 1995;333(10):621627.

110. Kobashigawa JA, Moriguchi JD, Laks H, et al. Ten-year follow-up ofa randomized trial of pravastatin in heart transplant patients. J Heart Lung Transplant. 2005;24(11):1736-1740.

111. Halle AA, DiSciascio G, Massin EK, et al. Coronary angioplasty, atherectomy and bypass surgery in cardiac transplant recipients. $J \mathrm{Am}$ Coll Cardiol. 1995;26(1):120-128.

112. Everly MJ, Bloom RD, Tsai DE, et al. Post transplant lymphoproliferative disorder. Ann Pharmacother. 2007;41(11):1850-1858.

113. Murakami M, Ito H, Harada E, et al. Long-term survival of xenogeneic heart grafts achieved by costimulatory blockade and transient mixed chimerism. Transplantation. 2006;82(2):275-281.

114. Adams AB, Williams MA, Jones TR, et al. Heterologous immunity provides a potent barrier to transplantation tolerance. J Clin Invest 2003;11(12):1887-1895. 